\title{
Development of LHRH-a Copolymer Pellet Polymerized by Ultraviolet and Its Application for Maturation in Red Sea Bream Pagrus major during the Non-Spawning Season
}

\author{
Michiya Matsuyama, ${ }^{{ }_{1}}$ Minoru Hamada, ${ }^{* 1}$ Taisuke Ashitani, ${ }^{* 1}$ \\ Masaaki Kashiwagi, ${ }^{* 1}$ Toshio Iwai, ${ }^{* 1}$ Koichi Okuzawa, ${ }^{* 2}$ \\ Hideki Tanaka, ${ }^{* 2}$ and Hirohiko Kagawa*2 \\ (Received January 25, 1993)
}

\begin{abstract}
A method is described for preparing a nonbiodegradable copolymer pellet containing luteinizing hormone-releasing hormone analogue (LHRH-a), des Gly ${ }^{10}$-[D-Ala ${ }^{6}$ LHRH ethy]amide, polymerized by ultraviolet rays to produce sustained hormone release. The pellet was applied to induce gonadal development and maturation in red sea bream Pagrus major during the non-spawning season, from November to December.

Single implantation of a copolymer pellet containing $100 \mu \mathrm{g}$ LHRH-a induced gonadal development and spawning in completely immature fish 18 days after implantation, about six months prior to the nutural spawning season. Fish implanted with a $50 \mu \mathrm{g}$ LHRH-a copolymer pellet or a control pellet were not induced to spawn. The histopathological findings of muscular tissues surrounding the implant showed that no inflammatory response to a foreign body appeared even one month after implantation. Results from the present study indicate that the LHRH-a copolymer pellets prepared by us have several features: (1) the pellets can be prepared easily and mass-produced at one time, (2) the pellets are useful for long-term hormone therapy in inducing sexual maturation in fish requiring a series of hormone treatments, and (3) the copolymer has good biocompatibility. However, the fertility rates of eggs produced were low. Further investigation is necessary to devise an effective method for obtaining more viable eggs by the use of copolymer pellets.
\end{abstract}

The use of synthetic luteinizing hormone-releasing hormone (LHRH) or its analogue (LHRH-a) has been shown to stimulate oocyte maturation and ovulation in several fishes (for a review, see Donaldson and Hunter, ${ }^{12}$ Zohar $^{2}$ ). However, the injection of the LHRH resulted in the quick disappearance of LHRH from the blood stream, probably due to the rapid breakdown of peptide in the body. ${ }^{3-5}$ Thus, the injection of LHRH is not always adequate for inducing the maturation of fish when it requires long-term hormone treatment. To prolong the hormone release in the blood stream, an LHRH cholesterol pellet has been developed and applied for inducing maturation and spawning in some fishes. ${ }^{8)}$ Cholesterolcellulose pellets containing $20-100 \%$ cellulose have been potentially useful with mature fish that require a rapid LHRH stimulus for final oocyte maturation and spawning, and 95 or $100 \%$ cholesterol pellets have shown the suitability for sustained release in fish requiring days for final oocyte maturation or in fish spawning on several successive days. ${ }^{\text {? }}$

Recently, a nonbiodegradable copolymer pellet containing leuprolide (des Gly ${ }^{10}$-[D-Leu $\left.{ }^{8}\right]$ LHRH ethylamide) has been developed for therapeutics of prostate cancer, ${ }^{8, \theta)}$ showing a slow and constant release of LHRH-a for 250 days. ${ }^{82}$ This copolymer, consisting of hydrophobic diethylene glycol dimethacrylate and hydrophilic polyethylene glycol \#600 dimethacrylate monomer, needs $\gamma$-ray irradiation from ${ }^{60} \mathrm{Co}$ for polymerization. Hirose et $a .^{103}$ applied this copolymer pellet containing native LHRH and LHRH-a (des Gly ${ }^{10}-\left[\mathrm{D}-\mathrm{Ala}^{6}\right.$ ] LHRH ethylamide) for the first time for the control of ovulation in mature ayu Plecoglossus altivelis,

*1 Faculty of Bioresources, Mie University, Kamihama, Tsu, Mie 514, Japan（松山倫也，浜田 稳，芦 谷泰輔，柏木正章，岩井寿夫：三重大学生物資源学部).

*2 National Research Institute of Aquaculture, Nansei, Mie 516-01, Japan (奥澤公一，田中秀樹，香川 浩彦: 養殖研究所). 
and succeeded in inducing ovulation in all fish in 3 days following pellet implantation. In vitro release of hormone from the copolymer pellet showed a constant rate of $0.65-1.36 \mu \mathrm{g} / \mathrm{day}$ over 75 days. ${ }^{10)}$ These results indicate that these copolymer pellets would be expected to be useful for the induction of sexual maturation in immature fish by long-term hormone treatment. However, the use of $\gamma$-rays from ${ }^{\circ 0} \mathrm{Co}$ in the pellet preparation may prove to be a disadvantage for the utilization and spread of such copolymer pellets in common hatcheries.

More recently, we have noticed a new type of resin, Lowicryl $\mathrm{K} 4 \mathrm{M}$, an embedding media for electron microscopy, which is photopolymerized by long wavelength $(360 \mathrm{~nm})$ ultraviolet light at even lower temperatures. In the present study, we describe a simple procedure for the preparation of LHRH-a (des Gly ${ }^{10}$-[D-Ala $\left.{ }^{\circ}\right]$ LHRH ethylamide) copolymer pellets using Lowicryl K4M as carriers, and test the potency of these pellets for inducing gonadal development and maturation in sexually immature red sea bream Pagrus major during the non-spawning season.

\section{Materials and Methods}

Hormones and Preparation of Copolymer Pellet

LHRH analogue (LHRH-a), des Gly ${ }^{10}$-[D$\mathrm{Ala}^{\mathrm{B}}$ ] LHRH ethylamide, was obtained from Sigma Chemical Co. (USA). Lowicryl K4M was purchased from TAAB Co. (UK).

A nonbiodegradable copolymer was prepared by ultraviolet-induced photopolymerization at low temperature. Lowicryl $\mathrm{K} 4 \mathrm{M}$ which has hydrophilic properties, consists of three components, namely monomer, crosslinker and initiator. The composition of Lowicryl $\mathrm{K} 4 \mathrm{M}$ is as follows;

Hydroxypropyl methacrylate 48.4 weight $\%$, monomer

Hydroxyethyl acrylate

$$
23.7 \text { weight } \% \text {, monomer }
$$

n-Hexyl methacrylate

$$
9.0 \text { weight } \% \text {, monomer }
$$

Triethylene glycol dimethacrylate

$$
13.9 \text { weight } \% \text {, crosslinker }
$$

Benzoin methyl ether

$$
\text { photo-initiator }
$$

The hardness of the pellet may be varied by incorporating more or less crosslinker in the resin mixture (more closslinker produces harder blocks). Three types of pellets in hardness were prepared. After mixing of the monomer $(17.3 \mathrm{~g})$ and cros- slinker $(2.7,2.4$, or $2.1 \mathrm{~g})$ for $15 \mathrm{~min}$, the initiator $(0.1 \mathrm{~g})$ was added and mixed for $30 \mathrm{~min}$. The mixture containing $2.7 \mathrm{~g}$ of crosslinker produces average hardness when preparing blocks for electron microscopy. Five mg LHRH-a was dissolved in $3 \mathrm{~m} l$ of the resin mixture and each $30 \mu l$ of the mixture was dispensed into translucent tubes made of polytetrafluoroethylene $(2 \mathrm{~mm}$ in diameter). Both ends of the tubes were sealed with sealing wax for hematocrit capillary. The above procedures were carried out under a continuous supply of nitrogen gas at $-10^{\circ} \mathrm{C}$, which prevents the incorporation of oxygen. The sealed tubes were placed in a UV-polymerizer (D.S.K. Model TUV-100, Dosaka EM Co., Japan) equipped with two 8-watt UV lamps $360 \mathrm{~nm}$ in wavelength, and were irradiated for $36 \mathrm{~h}$ with UV-rays at $-40^{\circ} \mathrm{C}$. The products, $2 \mathrm{~mm}$ in diameter and $6 \mathrm{~mm}$ in length, each containing $50 \mu \mathrm{g}$ LHRH-a, were removed from the mould and stored at $-30^{\circ} \mathrm{C}$ until use. Control pellets were constructed in the same way but contained no LHRH-a.

\section{In Vitro Release Test of LHRH-a}

In vitro release of hormone from the copolymer pellets was tested as follows. Twenty pellets each from three types of pellet were immersed in a flask filled with $5 \mathrm{~m} l$ of $0.1 \mathrm{M}$ phosphate buffer (pH 7.2) as an elution medium. The flask was shaken at a rate of 100 times a minute at $20^{\circ} \mathrm{C}$. The elution medium was exchanged daily with a fresh medium. At appropriate time intervals, the drug concentration in the medium was measured at $640 \mathrm{~nm}$ with a Hitachi Model 100-10 spectrophotometer by bicinchoninic acid protein assay method using the Pierce Micro BCA Protein Assay Reagent (Pierce Co, USA). The values were represented by the mean of triplicate tests. Hormone-free control pellets were examined in a same manner, and the true amount of LHRH-a released from the pellets was obtained.

\section{Animals and Hormone Implantation}

Sexually regressed two-year-old red sea bream (average weight $1.4 \mathrm{~kg}$ ), originating from a commercial fish farm, were kept in a $5 \times 5 \times 5 \mathrm{~m}$ sea pen until the experiments. The natural breeding season of red sea bream in mid Japan is April to May. The induced maturation experiments were carried out during November-December 1990, when fish have completely immature gonads. Thirty-four fish were divided into four groups and the following treatments were accomplished: 
initial control (not treated), final control (hormone-free pellets implanted), LHRH-a $50 \mu \mathrm{g} /$ fish, and LHRH-a $100 \mu \mathrm{g} /$ fish (two pellets implanted). As there was no significant difference in the in vitro hormone release pattern in the three types of pellets as described in the results section, a pellet consisting of $2.7 \mathrm{~g}$ crosslinker and $17.3 \mathrm{~g}$ monomer was administered to fish. No attempt was made to identify the sexes of fish in order to minimize any stress associated with handling. On November 8, after anaesthetization with 2-phenoxyethanol $(100 \mathrm{ppm})$, the pellets were implanted intramuscularly just below the dorsal fin using a $2-\mathrm{mm}$ trochar inserted through a $10 \mathrm{~mm}$. Fish of the initial control were killed and their gonads were examined histologically. After pellet implantation, fish were placed in 1000 -liter round fiberglass tanks with aerated running seawater at a natural temperature of about $16-17^{\circ} \mathrm{C}$, and were fed with a commercial food pellet every day. Spawning was monitored every day by examining eggs which overflowed from tanks into collecting nets, and when eggs were found they were counted and the fertility rate was examined.

All pellet-implanted fish were killed between 9:00 and 13:00 on December 8 by decapitation, their sexes were checked, and their gonads were removed and weighed. Gonadosomatic index (GSI) was calculated by gonad weight $(\mathrm{g}) \times 100 /$ body weight (g). Gonads and muscular tissue around the pellet were fixed in Bouin's fixative for the preparation of paraffin section. Sections were made at $4 \mu \mathrm{m}$ thickness and stained with hematoxylin and eosin. Developmental stages of oocytes of red sea bream were followed according to Matsuyama et al. ${ }^{11)}$ Data were represented by mean and SEM, and single classification ANOVA and Student's t-test were used to analyze the data.

\section{Results}

The in vitro release of $\mathrm{LHRH}$-a from the pellets is shown in Fig. 1. In spite of the variation in the hardness of the pellet, the patterns of hormone release into the elution medium in the three types of pellet were similar to each other. The quantity of release was not significantly different among the pellet types on different days (ANOVA, $P<0.05$ ). The mean concentration of LHRH-a in the elution medium from the three types of pellets peaked after 1 day at around $1.7 \mu \mathrm{g}$, then decreased rapidly after 2 days to $0.5 \mu \mathrm{g}$. There was a constant decrease in the rate of hormone release for about 3 months after 5 days, and even after 90 days $0.03 \mu \mathrm{g}$ of LHRH-a was released from each pellet per day.

In the group of LHRH-a $100 \mu \mathrm{g} /$ fish, the first spawned eggs (about 60,000 in number) were found

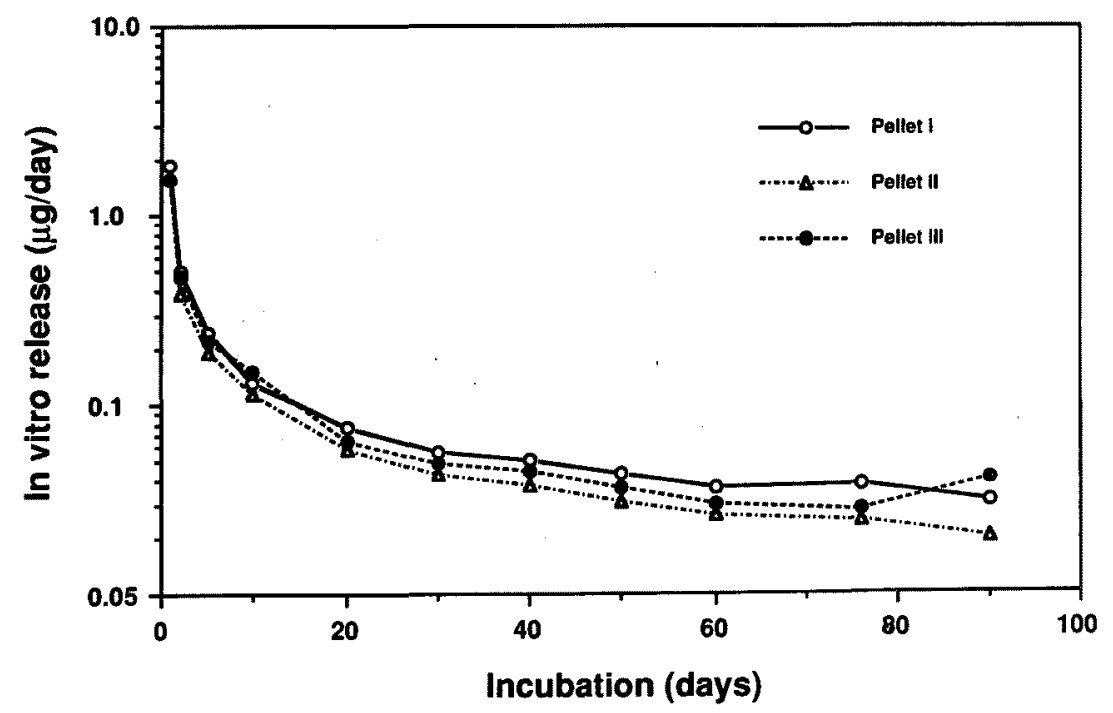

Fig. 1. In vitro daily release of LHRH-a from a copolymer pellet. Initial content of drug charged into a pellet is $50 \mu \mathrm{g}$.

Pellet I, II, and III contain crosslinker $2.7 \mathrm{~g}, 2.4 \mathrm{~g}$, and $2.1 \mathrm{~g}$, respectively, mixed with $17.3 \mathrm{~g}$ of monomer in the resin mixture. The ordinate is logarithmic. 


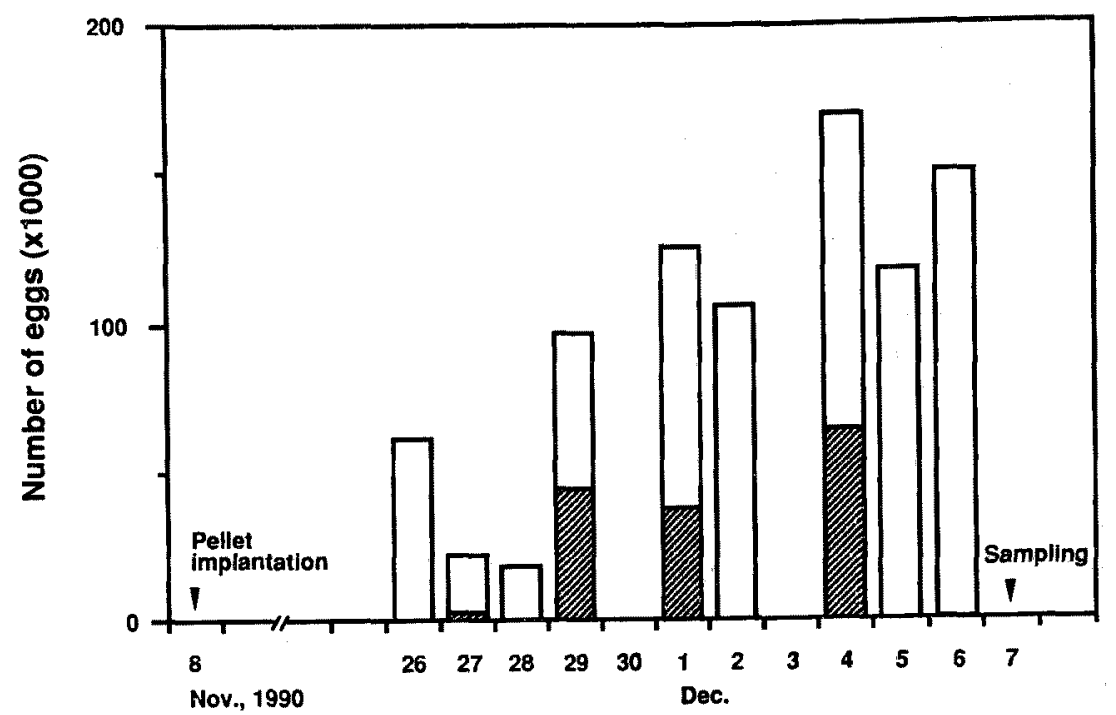

Fig. 2. Number of eggs spawned by a group of fish implanted with LHRH-a $100 \mu \mathrm{g}$. The fertility rate was examined four times, on November 27 and 29, and December 1 and 4 , and the shaded portions show fertilized eggs. The LHRH-a $50 \mu \mathrm{g} /$ fish group and the control did not produce.

on 26 November, 18 days after pellet implantation (Fig. 2). Spawned eggs were observed every day (with the exception of two days) until the end of the experiment, and showed a gradual increase in number as time went on. In both groups of LHRH-a $50 \mu \mathrm{g} /$ fish and the final control (hormone-free pellet implanted), no spawned eggs were observed during the experimental period. The gonads of the fish at the start of the pelletimplant experiment (initial control) were completely immature; only pre-vitellogenic oocytes at the peri-nucleolus stage were present in the ovaries (Fig. 3A) and predominating spermatogonia in the testes (Fig. 3B). Two of the five females in the group of $100 \mu \mathrm{g} /$ firsh had hydrated mature oocytes in their ovaries (Fig. $3 \mathrm{C}$ ), and three female fish had yolk-accumulated ovaries (Fig. 3D). Testes in all males (three fish) in this group showed active spermatogenesis (Fig. 3E), and a small amount of milt flowed out by soft abdominal massage. Although one female in the group of LHRHa $50 \mu \mathrm{g} /$ fish had early vitellogenic oocytes in the ovary, ovaries of the remaining four females contained only pre-vitellogenic oocytes at the perinucleolus and oil droplet stages. Although the testes of male fish in this group showed predominating spermatogonia as in the testes of the inital control, small amounts of spermatozoa were observed in the lobular lumens (Fig. 3F). No dif- ferences in gonadal histology between initial and final controls were recognized in either female or male. Thus, by single implantation of the copolymer pellets containing $100 \mu \mathrm{g}$ of LHRH-a, gonadal development, maturation, and spawning were induced in immature red sea bream 18 days after implantation.

The fertility rates of spawned eggs were examined at four different times, and the values were in a relatively low range $(12-46 \%)$ (Fig. 2).

The gonadosomatic indices (GSI) of fish in the initial control were very low, $0.8 \pm 0.02$ in females and $0.2 \pm 0.02$ in males (Fig. 4). The GSI values of fish of the LHRH-a $100 \mu \mathrm{g} /$ fish group were $3.5 \pm 1.4$ in females and $0.9 \pm 0.2$ in males, showing a rapid increase due to their gonadal development and maturation after pellet implantation. In both sexes there were significant differences in GSI values between the initial control and LHRH-a $100 \mu \mathrm{g} /$ fish group $(\boldsymbol{P}<0.01$ in females, $\boldsymbol{P}<0.05$ in males by t-test), whereas no significant difference was found between the initial control and $50 \mu \mathrm{g} /$ fish group or the final control $(P<0.05)$.

Copolymer pellets were implanted in the back muscular tissue below the dorsal fin. In all fish implanted with the pellets, no inflammatory response to a foreign body appeared even one month after implantation. Microscopic observations showed that the surface of the implant was 


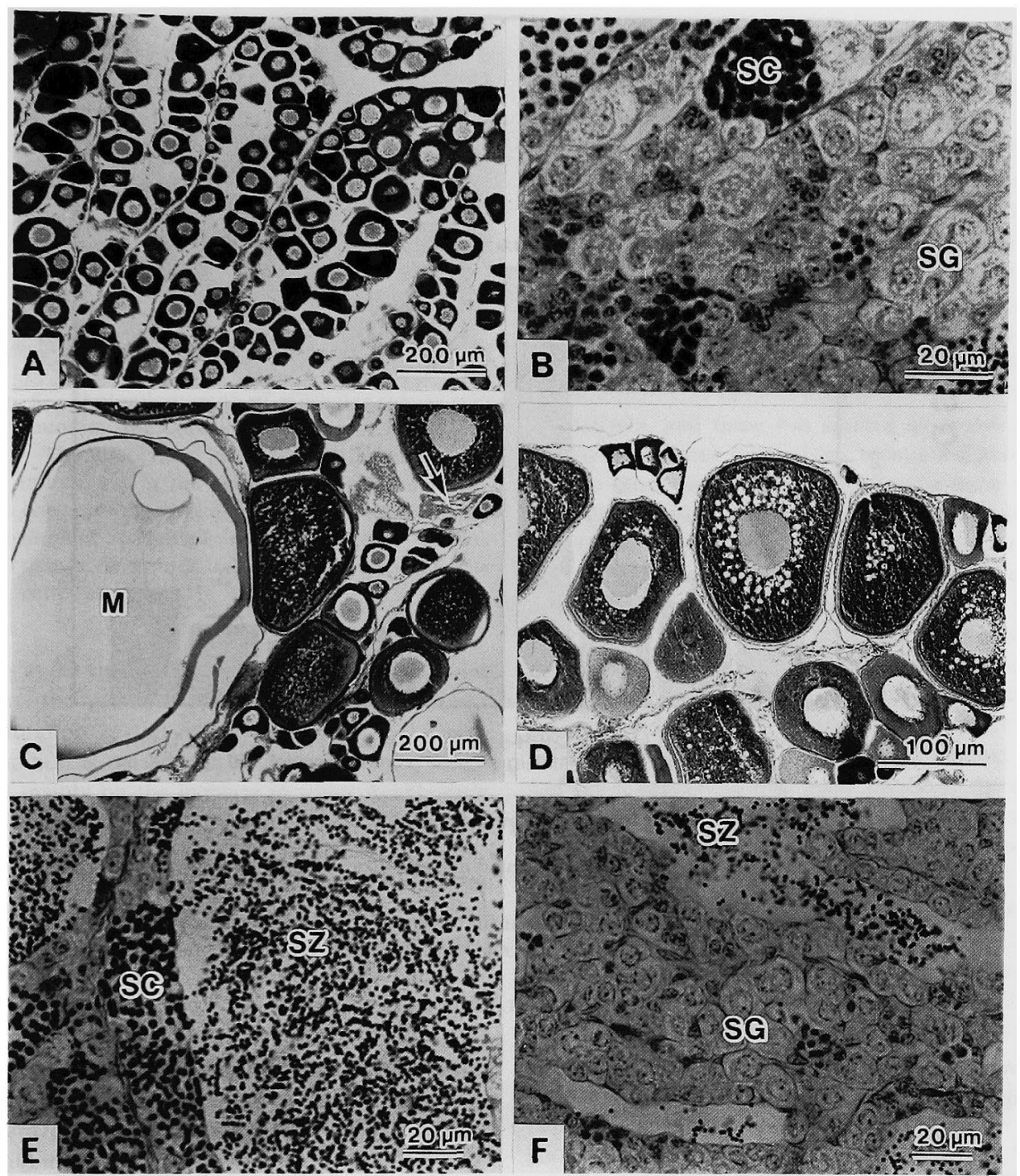

Fig. 3. Photomicrographs of gonads in fish implanted with copolymer pellets containing different contents of LHRH-a.

(A), immature ovary composed of only pre-vitellogenic oocytes from a fish of the initial control. (B) immature testis in which spermatogonia predominate, from a fish of the initial control. SG, spermatogonia; SC, spermatocytes. (C), mature ovary of fish implanted with a pellet containing $100 \mu \mathrm{g}$ of LHRH-a. Arrow indicates postovulatory follicles. M, mature oocyte. (D), yolk-accumulated ovary of fish implanted with a pellet containing $100 \mu \mathrm{g}$ of LHRH-a. (E), testis of fish implanted with a pellet containing $100 \mu \mathrm{g}$ of LHRH-a showing active spermatogenesis. SC, spermatocytes; SZ, spermatozoa. (F), testis of fish implanted with a pellet containing $50 \mu \mathrm{g}$ of LHRH-a, showing a predominating spermatogonia and the presence of a small amount of spermatozoa in the lobular lumen. SG, spermatogonia; SZ, spermatozoa. 


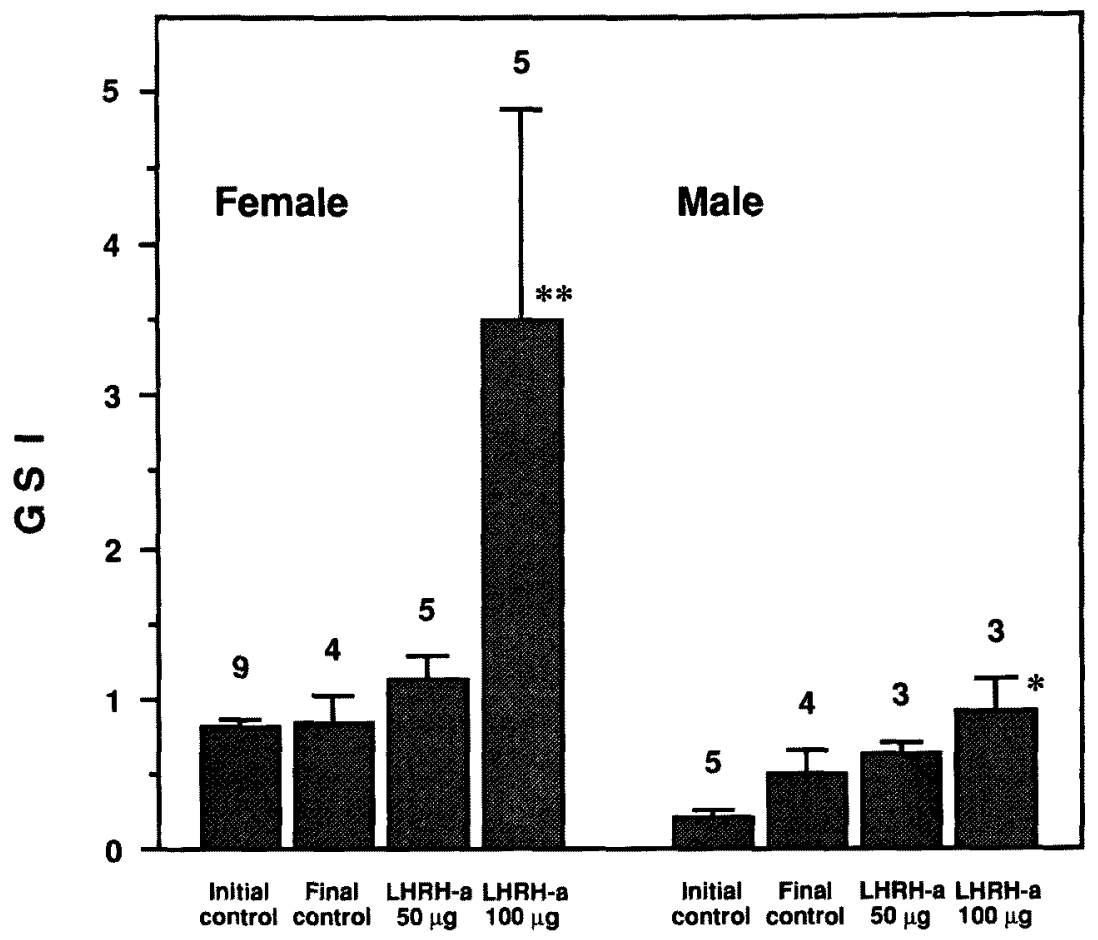

\section{Treatment}

Fig. 4. Effect of implanting pellets containing different doses of LHRH-a in red sea bream on gonadosomatic index (GSI).

Values represent mean $\pm S E M$. The initial control shows fish killed on the day when the experiment started (Nov. 8, 1990), and the final control represents fish implanted with hormone-free pellets.

**, $P<0.01 ; *, 0.01<P<0.05$ by t-test.

covered completely by a thin fibrous tissue layer (Fig. 5).

\section{Discussion}

By single implantation of a copolymer pellet containing $100 \mu \mathrm{g}$ LHRH-a in the winter season, gonadal development and maturation was induced in both sexes of immature red esa bream, and the first spawning was observed 18 days after implantation. Ovarian development in the red sea bream is asynchronous. Oocytes undergo maturation and ovulation at 24 hours intervals ${ }^{11}$ ) and females spawn daily over periods of time ranging up to two months. ${ }^{12}$ ) Germinal vesicle breakdown and hydration indicating final oocyte maturation occurred between 7:00 and 13:00. In fish which spawn daily, it took about 24 hours for the disappearance of newly formed postovulatory follicles (POF). Therefore, during the spawning season, between 7:00 and 13:00 both mature oocytes and POF can be observed in the ovary of fish which spawn daily. ${ }^{11}$ The present study demonstrated that 2 out of 5 females treated with LHRH-a $100 \mu$ g pellets, sampled at around noon, had mature oocytes and POF simultaneously, suggesting that these fish spwan daily until sacrifice. Thus, single implantation of an LHRH-a copolymer pellet could induce daily spawning of the red sea bream 6 months prior to the natural spawning season. The red sea bream is one of the most important fish for aquaculture in Japan, and there have been several trials to accelerate gonadal maturation for the early supply of fry. They were carried out by controlling the water temperature during the prespawning season. For example, by elevating water temperature to $16^{\circ} \mathrm{C}$ from below $14^{\circ} \mathrm{C}$, Fukusho ${ }^{13)}$ obtained spawned 


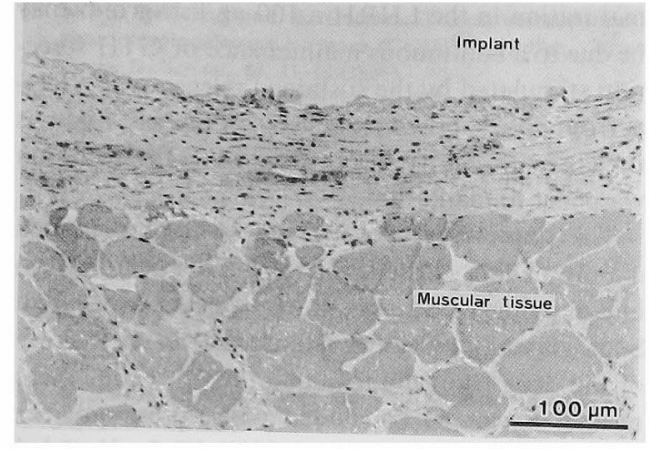

Fig. 5. Photomicrograph of muscular tissues surrounding the copolymer pellet.

The copolymer pellet was implanted intramuscularly in the backs of red sea bream for one month. The tissues surrounding the implant consisted mainly of thin fibrous tissues, and no inflammatory response the pellet appeared.

eggs at the end of March, about twenty days earlier than the natural spawning season. Gonadal maturation of the red sea bream in the natural condition is considered to depend on day-length and mainly on the increase in water temperature, and spawning commonly starts when the water temperature exceeds $16^{\circ} \mathrm{C} .1^{14,15)}$ Although Fukusho's experiment $^{13}$ ) utilized the temperature-increase method, the fish used in his study seemed to complete vitellogenesis and to induced only final maturation and the subsequent spawning. The present study showed that LHRH-a copolymer pellets could induce the onset of vitellogenesis, final maturation, and spawning given the appropriate water temperature, but with disadvantagous photo-periodic conditions and short daylength for gonadal development. The use of LHRH-a copolymer pellets is more effective in phase-shift spawning in red sea bream than controlling the water temperature.

A study which monitored egg numbers spawned and spawning times in a single female during the spawning season showed poor egg numbers and discontinuous spawning during the early and late periods of the spawning season, whereas a large amount of spawned eggs and daily spawning were observed during the mid period of the spawning season. ${ }^{12)}$ If the duration of rearing of fish which had been pellet-implanted in this study were to be prolonged, an increase in the number of spawned eggs and the regular continuation of daily spawning might be expected.

The fertility rates were much lower in the LHRH-a $100 \mu \mathrm{g} /$ fish group (12-46\%) than those in the eggs obtained from fish during the natural spawning season, April to May $(90 \%$ and over in mean values $\left.{ }^{12)}\right)$. The GSI values in both sexes of red sea bream in the natural spawning season are approxymately 5 to $10 .{ }^{16,17}$ ) Two mature fish of 5 females implanted with $100 \mu \mathrm{g}$ LHRH-a pellets had sufficient GSI value as mature fish, 7.7 and 5.9, respectively, and these fish seemed to spawn regularly at 24 hour intervals as mentioned above. On the other hand, in male fish in the same experimental group, the GSI showed low values $(0.9 \pm 0.2)$, and a small amount of milt was stripped by abdominal massage. Taking these results into consideration, the low fertility rates in the present study may be due to insufficient maturation in the testes. Our recent similar experiments using LHRH-a contained in the cholesterol pellet or osmic pump ${ }^{10), *}$ showed that male GSI values increased in a dose-dependent manner of LHRH-a, suggesting that more hormone therapy is necessary for the testicular development and maturation of red sea bream out side of the spawning season.

In the in vitro experiment, the LHRH-a release profile from the copolymer pellet showed an initial burst, a high dose LHRH-a release, and a subsequent lower and prolonged release of LHRH-a. It is unclear whether the initial burst, the subsequent lower prolonged release of $\mathrm{LHRH}-\mathrm{a}$, or both the initial and the prolonged LHRH-a release profiles are required for the induction of gonadal development and the maturation of the red sea bream. A single injection of LHRH-a (100 $\mu \mathrm{g} /$ fish ranging 1 to $1.5 \mathrm{~kg}$ in $\mathrm{BW}$ ) failed to induce maturation in either sex of immature red sea bream during the winter season such as in this study (unpublished data). These results suggest that gonadal development and spawning in this species during the winter season can be successfully induced by continuous LHRH-a administration over a certain dose for a specific period within 18 days.

The doses of LHRH-a in this study $(72 \mu \mathrm{g}$ or

* H. Takeuchi, A. Ohno, M. Matsuyama, M. Kashiwagi, T. Iwai, K. Hirose, and H. Kagawa: Inducing spawning of the red sea bream in the winter season by LHRH-a. Abst. Ann. Meet. Japan. Soc. Sci. Fish., April, 1993, p. 39. 
$36 \mu \mathrm{g} / \mathrm{kg} \mathrm{BW})$ are within the range reported to induce ovulation in milkfish $(20-100 \mu \mathrm{g} / \mathrm{kg}$ in cholesterol and cellulose pellets; $;{ }^{18,10>}$ apparentely $40 \mu \mathrm{g} / \mathrm{kg}$ in cholesterol pellets $\left.{ }^{20}\right)$. In the present study, $100 \mu \mathrm{g}$ LHRH-a treatment was successful while $50 \mu \mathrm{g} \mathrm{LHRH-a} \mathrm{therapy} \mathrm{was} \mathrm{completely} \mathrm{in-}$ effective. In our previous similar study, implantation of cholesterol pellets containing $100 \mu \mathrm{g}$ LHRH-a successfully induced spawning in one out of 3 female red sea bream during the winter season, while none of 5 females was induced to maturation by $50 \mu \mathrm{g}$ LHRH-a cholesterol pellet treatment. ${ }^{21}$ ) These results suggest that there is a distinct difference in effectiveness for inducing gonadal development and maturation in immature red sea bream between two doses of LHRHa. Although we do not explain such a big difference produced by a small change in hormone dose, when the pellet containing $100 \mu \mathrm{g} \mathrm{LHRH-a}$ is implanted there may be a sustained LHRH-a release from the pellet at a certain critical plasma level which causes sufficient and continuous GHT secretion for inducing gonadal development and maturation in the red sea bream.

In the present study of in vitro release rate, we did not measure the actual levels of LHRH-a, but rather the levels of total proteins. In as far as we measure the released LHRH-a from the copolymer pellets under in vitro condition, protein measurements can be considered as indicative of the LHRH-a level. However, recent studies on degradations of GnRH or its analogs after injection into female Sparus aurata, a very closely related species of red sea bream, showed that enzymatic cleavage rapidly terminates GnRH bioactivity in vivo., ${ }^{4} 5$ Consequently, the degradative process of LHRH-a released from copolymer pellets in vivo should be examined by rapid RIA or HPLC assay, and this study is presently being investigated in our laboratory.

Zohar $^{2}$ examined the changes in plasma GHT levels in female Sparus aurata with vitellogenic oocytes following the administration of the GnRHa ([D-Ala ${ }^{8}-$ Pro $\left.^{8}\right]$ LHRH ethylamide) via various methods. The injection of the GnRH-a at a dose of $7.5 \mu \mathrm{g} / \mathrm{kg} \mathrm{BW}$ induced a GTH surge, which at 24 hours was in its downward phase, and GTH levels were back to the baseline 48 to 72 hours after the injection. Contrarily, cholesterol pellets containing GnRH-a (content unknown) induced a continuous release of GTH throughout the experimental period of 10 days. Thus, in the present study, it is likely that gonadal development and maturation in the LHRH-a $100 \mu \mathrm{g} /$ fish group may be due to a continuous maintenance of GTH serection stimulated by the sustained release of LHRHa from the copolymer pellets. Further study is necessary to clarify the profiles of GTH secretion via pellet implantation.

The tissues surrounding the implant consisted mainly of thin capsules of fibrous tissues, and no infiammatory response to the pellet appeared. Such a layer significantly retarded the in vivo release of the drug from the formulation. ${ }^{22}$ From these results, it can be concluded that this copolymer has good biocompatibility and is scarcely degraded in vivo.

In conclusion, we developed LHRH-a copolymer pellets polymerized by ultraviolet and succeeded in inducing gonadal maturation and spawning in completely immature red sea bream six months prior to the natural spawning season by single implantation of pellets. Results from the present study indicate that the LHRH-a copolymer pellets prepared by us have several features: (1) the pellets can be prepared easily and mass-produced at one time, (2) the pellets are useful for long-term hormone therapy in inducing sexual maturation in fish requiring a series of hormone treatments, and (3) the copolymer has good biocompatibility. However, in the present study, the fertility rates of eggs produced were low. Further investigation is necessary to devise an effective method for obtaining more viable eggs by the use of copolymer pellets.

\section{Acknowledgements}

We wish to express our thanks to Dr. K. Hirose (National Research Institute of Aquaculture) for providing valuable suggestions, and to Dr. S. Matsuura (Kyushu University) for generously allowing us the use of the UV-polymerizer. This study was supported in part by a Grant-in-Aid (Bio Media Program) from the Ministry of Agriculture, Forestry and Fisheries (BMP-93-II-2-6).

\section{References}

1) E. M. Donaldson and G. A. Hunter: Induced final maturation, ovulation, and spermiation in cultured fish, in "Fish Physiology, Vol. IXB" (ed. by W. S. Hoar, D. J. Randall, and E. M. Donaldson), Academic Press, New York, 1983, pp. $351-403$,

2) Y. Zohar: Gonadotropin releasing hormone in spawning induction in teleosts: basic and applied considerations, in "Reproduction in Fish - Basic and Applied Aspects in Endocrinology and Genetics" (ed. by Y. Zohar and B. Breton), INRA Press, Paris, 1988, pp. 47-62. 
3) N. M. Sherwood and B. Harvey: Topical absotption of gonadotropin-releasing hormone ( $\mathrm{GnRH})$ in goldfish. Gen. Comp. Endocrinol., 61, 13-19 (1986).

4) A. Goren, Y. Zohar, M. Fridkin, E. Elhanati, and Y. Koch: Degradation of gonadotropin-releasing hormones in the gilthead seabream. Sparus aurato. I. Cleavage of native salmon GnRH and mammalian LHRH in the pituitary. Gen. Comp. Endocrinol., 79, 291-305 (1990).

5) Y. Zohar, A. Goren, M. Frikdin, E. Elhanati, and Y. Koch: Degradation of gonadotropin-releasing hormones in the gilthead seabream, Sparus aurata. II. Cleavage of native salmon GnRH, mammalian LHRH, and their analogs in the pituitary, kidney, and liver. Gen. Comp. Endocrinol., 79, 306-319 (1990).

6) Y. Zohar: Endocrinology and fish farming: Aspects in reproduction, growth, and smoltification. Fish Physiol. Biochem. 7, 395-405 (1989).

7) N. M. Sherwood, L.W. Crim, J. Carolsfeld, and S. M. Walters: Sustained hormone release. I. Characteristics of in vitro release of gonadotropin-releasing hormone analogue (GnRH-A) from pellets. Aquaculture, 74, 75-86 (1988).

8) T. Mashimo, K. Imai, H. Yuasa, H. Yamanaka, M. Yoshida, M. Asano, I. Kaetsu, and I. Yamazaki: Controlled slow release of drug from LH-RH agonist-vinyl copolymer composites having sandwich structure. Clin. Endocrinol, 34, 129-133 (1986) (in Japanese).

9) M. Yoshida, M. Asano, I. Kaetsu, K. Imai, H. Yuasa, H. Yamanaka, K. Shida, K. Suzuki, K. Wakabayashi, and I. Yamazaki: Pharmacological response in male rats with controlled release formulations of luteinizing hormone-releasing hormone agonist. Polymer J., 18, 287-296 (1986).

10) K. Hirose, H. Kagawa, M. Yoshida, M. Kumakura, and H. Yamanaka: Application of LHRH copolymer pellet for induction of final oocyte maturation and ovulation in ayu Plecoglossus altivelis. Nippon Suisan Gakkaishi, 56, 17311734 (1990).

11) M. Matsuyama, S. Adachi, Y. Nagahama, and S. Matsuura: Diurnal rhythm of oocyte development and plasma steroid hormone levels in the fernale red sea bream, Pagrus major, during spawning season. Aquaculture, 73, 357-372 (1988).

12) S. Matsuura, K. Maruyama, M. Furuichi, and M. Matsuyama: Daily spawning and quality of eggs in one female red sea bream Pagrus major. Suisanzoshoku, 36, 33-39 (1988) (in Japanese).

13) K. Fukusho: Present status and problems in mass fry production, in "Sea farming technology of red sea bream" (ed. by M. Tanaka and Y. Matsumiya), Koseisha-Koseikaku, Tokyo, 1986, pp. 9-25 (in Japanese).

14) M. Matsuyama: Red seabream, in "Reproductive rhythm in marine fish" (ed. by K. Hirose), Koseisha-koseikaku, Tokyo, 1991, pp. 78-91 (in Japanese).

15) K. Asahina: Reproductive cycle and its control, in "Suizoku hanshokugaku (Reproductive biology of aquatic animal)" (ed. by F. Takashima and I. Hanyu), Midori Shobo, Tokyo, 1989, pp. 103-131 (in Japanese).

16) K. Ouchi, $S$. Adachi, and $Y$. Nagahama: Changes in plasma levels of steroid homones during sexual maturation of female red seabream Pagrus major. Nippon Suisan Gakkaishi, 54, 585-591 (1988) (in Japanese).

17) K. Ouchi, S. Adachi, and Y. Nagahama: Changes in plasma levels of steroid hormones during sexual maturation of male red seabream Pagrus major. Nippon Suisan Gakkaishi, 54, 593-597 (1988) (in Japanese)

I8) C. L. Marte, N. M. Sherwood, L. W. Crim, and B. Harvey: Induced spawaing of maturing milkfish (Chanos chanos Forsskal) with gonadotropin-releasing hormone (GnRH) analogues administrated in various ways. Aquaculture, 60 , 303-310 (1987).

19) C. L. Marte, N. M. Sherwood, L.W. Crim, and J. Tan: Induced spawning of maturing milkfish (Chanos chanos) using human chorionic gonadotropin and mammalian and salmon gonadotropin releasing hormone analogues. Aquaculture, 73, 333-340 (1988).

20) C.S. Lee, C. S. Tamaru, C. D. Kelley, and J. E. Banno Induced spawning of milkfish, Chanos chanos, by a singte application of LHRH-analogue. Aquaculture, 58, 87-98 (1980).

21) M. Matsuyama, H. Kagawa, H. Takeuchi, M. Kashiwagi, T. Iwai, and K. Hirose: Effect of LHRH-a cholesterol pellet on gonadal development, maturation and spwaning in Pagrus major during winter season. Suisanzoshoku, 40, 159-165 (1992) (in Japanese).

22) M. Yoshida, M. Asano, I. Kaetsu, K. Nakai, H. Yamanaka, T. Suzuki, K. Shida, and $\mathrm{K}$. Suzuki: In vitro release of testosterone from vinyl polymer composites prerared by radiation-induced polymerization. Biomaterials, 4, 33-38 (1983). 